\title{
A Framework for a Knowledge Management System in a Cloud Computing Environment Using a Knowledge Engineering Approach
}

\author{
Anuchit Anupan, Prachyanun Nilsook, and Panita Wannapiroon
}

\begin{abstract}
This study aims to design a framework for a knowledge management system in a cloud computing environment using a knowledge engineering approach. The research comprised 2 steps: 1) analyzing and synthesizing the relevant literature with regard to knowledge management systems in a cloud computing environment using a knowledge engineering approach and 2) designing a framework for a knowledge management system in a cloud computing environment using a knowledge engineering approach. Data were analyzed using content analysis. A knowledge management system consists of four components as follows: 1) knowledge retrieval 2) knowledge storage 3) knowledge sharing and 4) knowledge publishing. The knowledge engineering approach consists of three components as follows: 1) knowledge acquisition 2) knowledge storage and 3) knowledge utilization.
\end{abstract}

Index Terms-Knowledge management system, cloud computing environment, knowledge engineering.

\section{INTRODUCTION}

Knowledge management systems are becoming important for organization when it comes to using information technology for the enhancement the knowledge management activities such as system development, file management [1] or classifying types of data. Knowledge engineering involves the sharing and application of knowledge [2] which can be built by various systems. The process of knowledge engineering involves an adoptable principle of engineering for the integration of knowledge with a computer system in order to solve problem [3].

Cloud computing is a new technology with regard to applications platforms which can be used for sharing and transferring data through information technology [4].

In this paper, we propose a framework for a knowledge management system in a cloud computing environment using a knowledge engineering approach obtained from the synthesis of documents and research studies related to the topic. A combination of knowledge management systems and knowledge engineering approaches consists of various processes such as that of knowledge acquisition, knowledge storage, and knowledge utilization. The knowledge engineering activities can be applied to knowledge

Manuscript received February 23, 2015; revised June 2, 2015.

The authors are with the Department of Information and Communication Technology for Education, Faculty of Technical Education, King Mongkut's University of Technology North Bangkok. 1518 Pracharat 1 Road, Wongsawang, Bangsue, Bangkok 10800 Thailand (e-mail: ju-anuchit@hotmail.com, panita.w@hotmail.com). management systems by means of the principles and various perspectives of system development.

\section{BACKGROUND FRAMEWORK}

The conceptual framework for a knowledge management system in a cloud computing environment using a knowledge engineering approach consists of:

\section{A. Knowledge Management System (KMS)}

A knowledge management system (KMS) is the system that supports the creation, transference and dissemination of knowledge to employees within an organization. We can use a knowledge management system to manage data and information using various tools for establishing a efficient knowledge [5]. A knowledge management system consists of hardware, software, people and the environment of a working organization [6]. A knowledge management system incorporates the tools and techniques needed to support the process of knowledge management in organizations such as the creation, sharing and use of knowledge [7]. A knowledge management system is defined as a process for promoting and focusing on management innovation [8]. Hoong [9] mentioned that a knowledge management system can be used for creating and sharing knowledge, including sharing across the network. The concept of a knowledge management system is relevant to using information technology. Gallupe [7] explained the tools for support of a knowledge management system as follows:

1) Intranet: An internet network system for use in an organization through web-browsing in order to share knowledge.

2) Information retrieval programs: Tools for searching for data and knowledge from databases or external knowledge sources.

3) Database management systems: Knowledge management system tools which can be accessed through the intranet and from an information network.

4) Knowledge-based or expert systems: Source of knowledge from experts which can be used continuously.

5) Groupware: Applications needed to communicate and collaborate within an organization. Moreover, Han [10] explained that knowledge transfer has three dimensions: knowledge acquisition, dissemination, and absorption, all of which can be applied in a knowledge management system to make it more efficient and able to support access to information on the part of a knowledge worker [11]. 


\section{B. Cloud Computing}

Cloud computing is a standard development in terms of information technology which has grown rapidly with regard to various services [12]. Talib [13] has found that in terms of the facilitation and sharing of knowledge within a work situation, cloud computing can be used collaboratively in this case. Furthermore, it is a new type of service and model for application to many systems. There are three types of cloud computing [14]: 1) private cloud: a cloud infrastructure for management and service use within an organization 2) public cloud: infrastructure of the cloud for service members and participants, including interested users who can access the system because it is open use by the general public and 3) hybrid cloud: the cloud infrastructure between a private cloud and a public cloud. It can be managed by the requirements of an organization. Fundamental cloud computing provides three main levels of service [15]-[17]: 1) infrastructure as a service (IaaS) is a data centre for the management and control of resources. It adjusts the requirements of the user through the Internet such as network resources, virtualization, memory resources, servers, storage devices, database resources, etc., [18]; 2) platform as a service (PaaS). This is a layer for application development, application servers and for testing software for individual users and corporate teams using tools and environment form providers [19] and 3) software as a service (SaaS). This is an application layer for delivered users through the Internet without installing software on devices. A SaaS can support users by reducing the time needed to build software. It therefore reduces costs in terms of the organization [20].

\section{Knowledge Engineering}

Knowledge engineering uses engineering principles and the integration of knowledge available to computers for solving complex problems. Knowledge engineering is the knowledge base that can be established and developed with regard to a knowledge based system through the use of good management in software engineering and computer science, such as using a normalization and indexing approach for knowledge storage with regard to computer systems [21]. Yang [3] explained that knowledge engineering is the process of finding knowledge through the use of a systematic structure which can be used for solving problems or making decisions. Knowledge engineering is the acquisition, structuring and refinement of knowledge, including knowledge analysis, knowledge formalization and knowledge reasoning [22]. Knowledge engineering consists of tools, techniques and processes that correspond to the knowledge system [23]. In addition, one of the advantages of knowledge management system application is knowledge manipulation, in which new knowledge can be generated from this knowledge management system by deploying knowledge engineering and a knowledge base [24].

\section{Methodology}

The framework for a knowledge management system in a cloud computing environment using a knowledge engineering approach can be divided into two phases:

1) Synthesizing the characteristics of the system in order to analyze and synthesize documents and research studies related to a framework consisting of i) the identification of source-related studies such as textbooks, academic articles and research articles ii) the classification of data corresponding to related theory in order to read and summarize important content for grouping with regard to the core idea of this study and iii) the analysis and synthesis of data in order to impose a framework.

2) Design the framework for a knowledge management system in a cloud computing environment using a knowledge engineering approach from phase 1 .

\section{RESUlTS AND DISCUSSION}

1) Synthesising the characteristics of the framework for the system consists of four knowledge management system components as follows: i) knowledge retrieval ii) knowledge storage iii) knowledge sharing iv) knowledge publishing. The knowledge engineering approach consists of three components as follows: i) knowledge acquisition ii) knowledge storage and iii) knowledge utilization. The findings from the study of a framework for a knowledge management system in a cloud computing environment using a knowledge engineering approach can be shown in Fig. 1 .

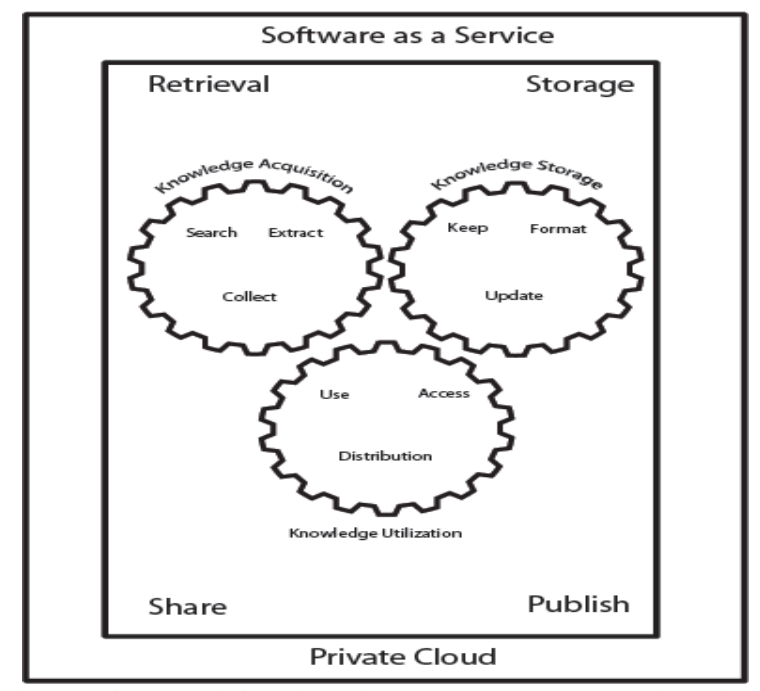

Fig. 1. A framework for a knowledge management system in a cloud computing environment using a knowledge engineering approach.

The framework shown in Fig. 1 consists of knowledge acquisition. This consists of explicit knowledge in a document format [2], [3], [22], [25] knowledge storage is the knowledge collected by a worker group whose language represents the knowledge to be stored. Knowledge can be classified in a database system [3], [23], [25], [26] knowledge utilization is the use of knowledge through a web browser related to cloud computing. Only members can use the knowledge base system within the knowledge server [2], [3], [22], [23], [25].

2) The knowledge management system framework consists of: i) a knowledge retrieval module ii) a knowledge storage module iii) a knowledge sharing module iv) a knowledge publishing module.

Moreover, a knowledge management system consists of the following abilities:

- link and transfer data and information. 
- link and transfer knowledge.

- link to database and source of knowledge from external organization resource.

- search for data, messages, pictures and documents.

- import and export data and resources.

- backup data quickly.

- secure the system.

This framework corresponds to Abdullah [27] suggestion that a knowledge management system offer for its processes through the knowledge life cycle which incorporates knowledge acquisition, knowledge storing, knowledge dissemination, and that a knowledge application and knowledge management system can be accessed through mobile computing [28].

3) The knowledge engineering approach consists of the following: i) knowledge acquisition: this approach induces perception, learning and communication. The sub-processes of knowledge acquisition include searching, extraction and collection ii) knowledge storage: this approach involves processes for updated data and information from users, including classified types of knowledge and the capture of knowledge for processing within a computer system and iii) knowledge utilization: this approach involves the process of data distribution and knowledge used for the benefit of an organization and individuals. Users can access knowledge through the Internet through the use of mobile devices or personal computers.

4) Cloud computing is a layer of Software as a Service (SaaS) and uses private cloud architecture for the development of the system. Users can use the system directly through the Internet, and without software having to be installed in a device. The user can access the system at all times and can access it from various devices. Furthermore, the user can share resources from a system because cloud computing is simple for users when it comes to accessing computing resources and maintaining the software [29].

5) The benefits of the proposed framework are as follows:

- Knowledge management system is central to knowledge storage in terms of cloud technology.

- Users can upload and download knowledge at all times. Users can improve the knowledge base in order to ensure that it is up-to-date.

- The system is easy to use in terms of distributing and sharing information. This allows individuals to knowledge easily and quickly.

- The system supports collaboration and discussion in order to achieve knowledge and ideas.

- The system can prevent the disappearance of knowledge in an organization.

\section{CONCLUSIONS}

The results of the proposed framework with regard to a knowledge management system in a cloud computing environment using a knowledge engineering approach implies that it consists of a number of important elements, i.e., a knowledge engineering approach which can be applied to establish, share, transfer and reuse knowledge in such a way as to enhance knowledge and cooperative learning activities [30]. The knowledge management system meets user's requirements in terms of the source of knowledge and various information with regards to the cloud computing environment through a web browser. In addition, cloud computing reduces the expense of hardware maintenance and software licenses as they affect the organization.

\section{ACKNOWLEDGMENT}

The researchers would like to thank Sisaket Rajabhat University, Vocational Education Technology Research Center and Innovation and Technology Research Center at Science and Technology Research Institute, and also Division of Information and Communication Technology for Education, Faculty of Technical Education, King Mongkut's University of Technology North Bangkok for support this research.

\section{REFERENCES}

[1] P. Nilsook and P. Wannapiroon, "International distance consulting via web conferencing," International Journal of Emerging Technologies in Learning, vol. 9, no. 4, pp. 60-64, June 2014.

[2] N. Matta and D. Monticolo, "Capitalization of collective knowledge: From knowledge engineering, multi-agent systems to CSCW and socio semantic web," in Proc. International Symposium on Collaborative Technologies and Systems, May 2010, pp. 13-20.

[3] X. Yang, "To facilitate knowledge management using basic principles of knowledge engineering," in Proc. Pacific-Asia Conference on Knowledge Engineering and Software Engineering, 2009, pp. 94-97.

[4] C. N. Liao, I. L. Chih, and Y. K. Fu, "Cloud computing: A concept framework for knowledge management system," Human Systems Management, vol. 30, no. 3, pp. 137-143, July 2011.

[5] F. McKenna. (April 2008). A knowledge management system a discourse. [Online]. pp. 1-9. Available: http://www.knowledgeonecorp.com/news/pdfs/A\%20Knowledge\%20 Management $\% 20$ System\%20- \%20A\%20Discourse.pdf

[6] S. Assegaff and A. R. C. Hussin. (2012). Review of knowledge management systems. [Online]. pp. 1-6. Available: http://arxiv.org/ftp/arxiv/papers/1212/1212.0387.pdf

[7] R. B. Gallupe. (2000). Knowledge management systems: Surveying the landscape. [Online]. pp. 1-17. Available: http://citeseerx.ist.psu.edu/viewdoc/download?di=10.1.1.104.7777\&r ep=rep1\&type $=$ pdf

[8] H. Jiang, C. Liu, and Z. Cui, "Research on knowledge management system in enterprise," in Proc. International Conference on Computational Intelligence and Software Engineering, December 2009, pp. 1-4.

[9] A. L. S. Hoong and T. M. Lim, "The use of knowledge management systems to support knowledge creation and sharing activities among employees - A survey based study of IT shared services company," in Proc. International Conference on Information Technology - New Generations, April 2012, pp. 175-181.

[10] W. Han and Y. Wang, "Knowledge management, knowledge management system, and organizational performance: An empirical study," in Proc. International Conference on Systems and Informatics, May 2012, pp. 2488-2492.

[11] H. Faris, S. Totaro, and A. Corallo, "Framework and implementation of a knowledge management system for aerospace collaborative working environments," in Proc. IEEE International Conference on Mobile Data Management, June 2011, pp. 92-97.

[12] A. Zimmermann, M. Pretz, G. Zimmermann, D. G. Firesmith, I. Petrov, and E. El-Sheikh, "Towards service-oriented enterprise architectures for big data applications in the cloud," in Proc. IEEE International Enterprise Distributed Object Computing Conference Workshops, 2013, pp. 130-135.

[13] A. M. Talib and R. Abdullah, "A model of information technology as a service (ITaaS) in cloud computing: A case of collaborative knowledge management system," in Proc. International Conference on Advanced Computer Science Applications and Technologies, November 2012, pp. 83-86. 
[14] B. P Rimal, E. Choi, and I. Lumb, "A taxonomy and survey of cloud computing systems," in Proc. Fifth International Joint Conference on INC, IMS and IDC, August 2009, pp. 44-51.

[15] C. Wang, Y. Huang, and Y. Huang. (2012). Interactive e-learning with cloud computing framework. [Online]. Available: http://download.springer.com/static/pdf/783/chp\%253A10.1007\%25 2F978-94-007-50869_41.pdf?auth66=1410158976_91adf898499a50 5d1e4dee688d9fa637\&ext=.pdf

[16] N. Sultan, "Cloud computing for education: A new dawn?" International Journal of Information Management, vol. 30, no. 2, pp. 109-116, 2010

[17] S. Gallagher and A. Dalgleish, VMware Private Cloud Computing with Vcloud Director, John Wiley \& Sons, Inc, 2013.

[18] T. Ercan, "Effective use of cloud computing in educational institutions," Procedia Social and Behavioral Sciences, vol. 2, no. 2, pp. 938-942, 2010.

[19] G. Yang, F. Zhou, and Z. Zhu, "The application of Saas-based cloud computing in the university research and teaching platform," in Proc. International Conference on Intelligence Science and Information Engineering, August 2011, pp. 210-213.

[20] Y. Wang and B. Jin, "The application of SaaS model in network education-take Google apps for example," in Proc. International Conference on Education Technology and Computer, vol. 4, pp. 191-194, June 2010.

[21] R. Abdullah, Z. D. Eri, and A. M. Talib, "A model of knowledge management system in managing knowledge of software testing environment," in Proc. Malaysian Conference in Software Engineering, December 2011, pp. 229-233.

[22] W. Wang, H. Wang, B. Yang, L. Liu, P. Liu, and G. Zeng, "A Bayesian network-based knowledge engineering framework for IT service management," IEEE Transactions on Services Computing, vol. 6, no. 1, pp. 76-88, March 2013.

[23] A. Preece, A. Flett, D. Sleeman, D. Curry, N. Meany, and P. Perry, "Better knowledge management through knowledge engineering," IEEE Intelligent Systems, vol. 16, no. 1, pp. 36-43, January /February 2001.

[24] H. C. Hassan, "A framework for user requirement assessment in technical education facility planning: A Knowledge engineering approach," Social and Behavioral Sciences, vol. 107, pp. 104-111, December 2013

[25] D. S. Darai, S. Singh, and S. Biswas, "Knowledge engineering: An overview," International Journal of Computer Science and Information Technologies, vol. 1, no. 4, pp. 230-234, 2010.

[26] L. F. Lai, "A knowledge engineering approach to knowledge management," Information Sciences: An International Journal, vol. 177, no. 19, pp. 4072-4094, October 2007.

[27] R. Abdullah, Z. D. Eri, and A. M. Talib, "A model of knowledge management system for facilitating knowledge as a service (KaaS) in cloud computing environment," in Proc. International Conference on
Research and Innovation in Information Systems, November 2011, pp. $1-4$.

[28] R. Abdullah and A. M. Talib, "Knowledge management system mode in enhancing knowledge facilitation of software process improvement for software house organization," in Proc. International Conference on Information Retrieval \& Knowledge Management, March 2012, pp. 60-63.

[29] J. Tao, J. Zhao, and L. Wang, "A methodology for building cloud services," in Proc. Spring Congress on Engineering and Technology, May 2012, pp. 1-4.

[30] H. C. Chu, G. J. Hwang, and C. C. Tsai, "A knowledge engineering approach to developing mindtools for context-aware ubiquitous learning," Computers \& Education, vol. 54, no. 1, pp. 289-297, January 2010

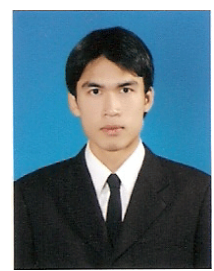

Anuchit Anupan was born in Sisaket Province, Thailand. He is a doctoral candidate in the information and communication technology for education program, Faculty of Technical Education, King Mongkut's University of Technology North Bangkok (KMUTNB) $\mathrm{He}$ research interests include knowledge engineering, knowledge management system, cloud computing, information and communication technology.

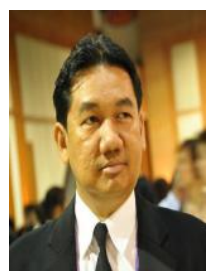

Prachyanun Nilsook is an associate professor at Division of Information and Communication Technology for Education, Faculty of Technical Education, King Mongkut's University of Technology North Bangkok (KMUTNB), Thailand. His research topics and interests include instructional design, e-learning, e-training, ICT management, ICT in education, knowledge management in higher education, human performance technology and imagineering.

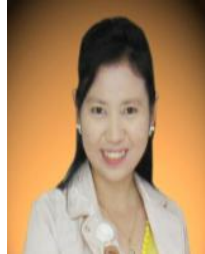

Panita Wannapiroon is an assistant professor at Division of Information and Communication Technology for Education, Faculty of Technical Education, King Mongkut's University of Technology North Bangkok (KMUTNB), Thailand. She has experience in many positions such as the director a Innovation and Technology Management Research Center, an assistant director of Online Learning Research Center, an assistant director of Vocational Education Technology Research Center, and an assistant director of information and communication technology in Education Research Center. She received Burapha University Thesis Award 2002. She is a membership of professional societies in ALCoB (Apec Learning Community Builders) Thailand, and Association for Education Technology of Thailand (AETT). 